(RESEARCH ARTICLE)

\title{
Study of traditional mycological knowledge of Pygmy and Bantu populations of Ogooué-Ivindo (Northeast of Gabon), Central Africa.
}

Eyi Ndong Hugues Calixte ${ }^{1, *}$, Ntoutoume Christian ${ }^{1}$, Bourobou Bourobou Judi Armel ${ }^{1}$ and Apinda Legnouo Emelie Arlette 2

${ }^{1}$ Institute for Agronomic and Forest Research (IRAF), Libreville, Gabon.

${ }^{2}$ Research Institute in Tropical Ecology (IRET), Libreville, Gabon.

Publication history: Received on 11 August 2020; revised on 29 August 2020; accepted on 30 August 2020

Article DOI: https://doi.org/10.30574/wjarr.2020.7.2.0298

\begin{abstract}
This article presents a comparative table of traditional mycological knowledge of Pygmy and Bantu populations of Ogooué-Ivindo (northeast of Gabon). An ethnomycological investigation was carried out in five villages of this province, to Pygmy (Baka) and Bantu (Kota and Kwélé) populations. The results of this study showed that traditional mycological knowledge of these populations varies according to ethnolinguistic membership, age and practiced activity. Bakoya Pygmies, who identified 93\% of total species, got the best fungi knowledge than Kota (60\%) and Kwele (33\%). However, there was no significant difference between the sex as regards traditional mycological knowledge within the same ethnic group. Concerning age groups, active population representatives (26-60 years) who identified all the inventoried species and young people (10-25 years) who identified $67 \%$ of species had better fungi knowledge than senior citizens (> 60 years old) who identified only $40 \%$ of inventoried species. About activities practiced by respondents, our results distinguish three homogeneous groups; the first made up of hunters who have the best traditional mycological knowledge ( $93 \%$ of identified species), followed by fishermen and farmers (67-73\% of identified species) and the last group is made up of pupils who manage to barely identify inventoried species.
\end{abstract}

Keywords: Traditional mycological knowledge; Bantus; Pygmies; Gabon.

\section{Introduction}

Non-timber forest products (NTFPs) extracted from the Gabonese forest allow rural populations to avoid food deficiencies and constitute a significant source of income. Among these, mushrooms are particularly sought after because of their high nutritional value and their market value. Mycological knowledge accumulated by villagers living in contact with or at the expense of ecosystems rich in mushrooms are considerable in Gabon as in all of tropical Africa. In some African countries, these knowledge, transmitted orally and in a traditional way, has been the subject of scientific studies, notably in Burundi [3], Malawi [8], Nigeria [9], Tanzania [7], DR Congo [4] and Zimbabwe [10]. Some of these works have made it possible not only to highlight the species of mushrooms consumed by local populations, but also to assess their nutritional contribution [13] and their market value [1, 11].

Our study is part of the promotion of traditional mycological knowledge of rural populations in Gabon. It took place in the province of Ogooué-Ivindo (Figure 1) characterized by the presence of one of the two largest pygmy groups in the country, in this case the Bakoya. The aim of this study is to draw up a comparative table of the traditional mycological knowledge of the Bakoya, Kota and Kwélé according to ethnicity, sex, age and practiced activity.

\footnotetext{
${ }^{*}$ Corresponding author: Eyi Ndong Hugues Calixte

Institute for Agronomic and Forest Research (IRAF), Libreville, Gabon.
} 


\section{Material and methods}

\subsection{Study environment}

Located in central Africa and straddling the equator, Gabon extends from $2^{\circ} 12^{\prime} \mathrm{N}$ to $3^{\circ} 55^{\prime} \mathrm{S}$ and from $8^{\circ} 20^{\prime} \mathrm{E}$ to $14^{\circ}$ $40^{\prime} \mathrm{E}$. It is limited to the North West by Equatorial Guinea, to the North by Cameroon, to the East and South by the Republic of Congo and to the West by the Atlantic Ocean on $750 \mathrm{~km}$ of coastline [12]. The country is divided into nine provinces. Our study took place in Ogooué-Ivindo province, located in the northeast of the country (Figure 1).

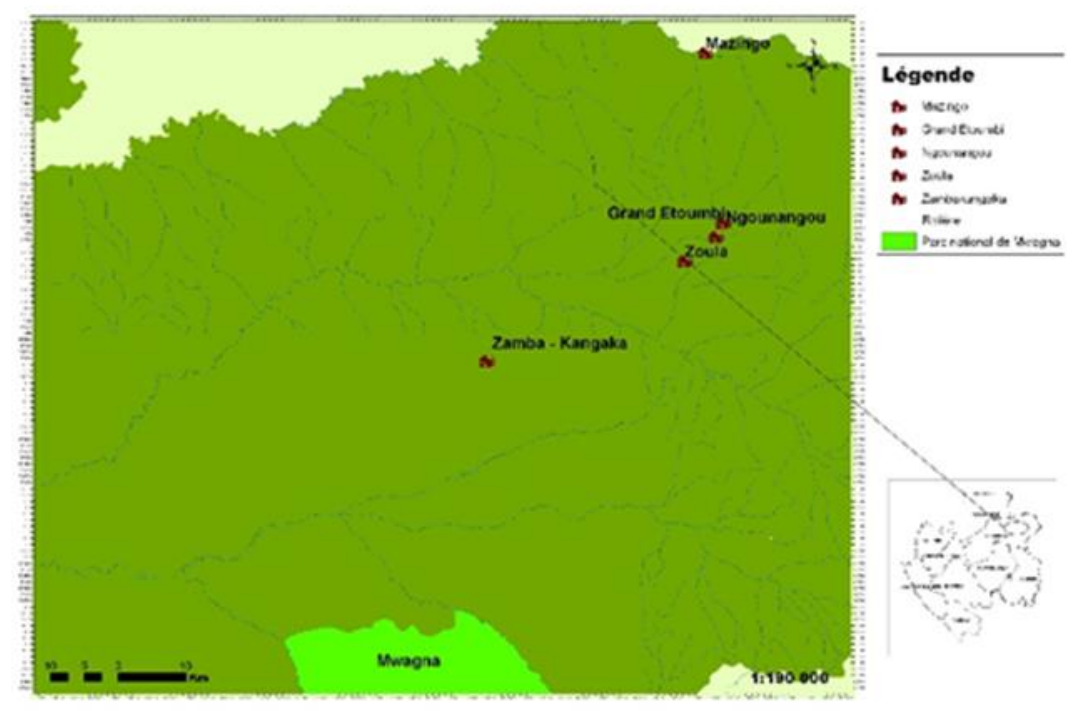

Figure 1 Location of the study site.

\subsection{Ethnomycological survey}

To assess the knowledge level of mushrooms by surveyed populations, 150 people of both sexes from the five selected villages were interviewed, using a questionnaire. This latest, whose design was based on the objectives to be achieved and on general information of the respondents, was presented in French. The questions and answers were translated into French by a local guide. In order to guarantee the reproducibility of our results, the surveys were repeated as many times as possible in the same places, and when possible, with the same people. Only confirmed data have been retained. The mushrooms consumed by the targeted ethnic groups were collected in the presence of their representatives. These collections have previously been described and identified according to the method proposed by Eyi Ndong et al. [6], then presented to respondents in order to assess their traditional mycological knowledge.

The choice of people and the number of people interviewed in the five villages selected depended on the parameters to be studied. Four parameters were thus monitored; namely ethnicity, age, sex and activity. According to age, three age groups (10-25, 26-60 and over 60) were selected, and thirty people were chosen per village (ten people per age group). Based on ethnicity and gender, three ethnic groups were the subject of the study; namely Bakoya (Pygmies), Kota and Kwélé (Bantus). Fifty people, twenty-five by sex, were selected by ethnic group. With regard to the activities practiced, five types of activity (agriculture, hunting, fishing, studies and invalids) were chosen and thirty people from different villages were selected by type of activity (six people per village and per activity). Three evaluation criteria were used to identify people with good traditional mycological knowledge; to know:

Being able to accurately recognize at least half of mushrooms consumed by the respondent ethnic group, on the basis of our inventory of fifteen taxa;

Remain faithful in its responses during the various fact-finding missions, around ten investigations were carried out;

Being able to distinguish different but very similar species mixed in a basket (the principle being to separate the mixture species by species). 


\subsection{Statistical analysis}

To compare traditional mycological knowledge of surveyed populations, statistical analysis was carried out with $\mathrm{R}$ software [14]. Traditional mycological knowledge was assessed depending on four main characteristics (age, sex, ethnicity, activity practiced) of individuals surveyed. Data relating to sex and ethnicity were analyzed together in order to appreciate the effect of gender-ethnicity interaction. As the variable to be explained is binary categorical, there are two possible responses (good traditional mycological knowledge and bad traditional mycological knowledge), the category "good traditional mycological knowledge" has been defined as "category of interest". So, we analyzed the probability that an individual is in this interest category, called "response probability" [15].

The statistical analysis was based on the logistic model (one model for each characteristic, expect for gender and ethnicity characteristics which were analyzed together). The fit to the data and the overall models explanatory capacity thus constructed were evaluated. The likelihood ratio test [16] allowed evaluating different explanatory variables effect and the comparison of the means of the different modalities of the factors was made using Tukey's method.

\section{Results}

Fifteen edible fungal taxa have been inventoried among Bakoya, Kota and Kwélé populations of Ogooué-ivindo ( Figure 2). Tables 1, 2 and 3 give the number of identified taxa by representatives of different ethnic groups, different activities practiced and different age groups.

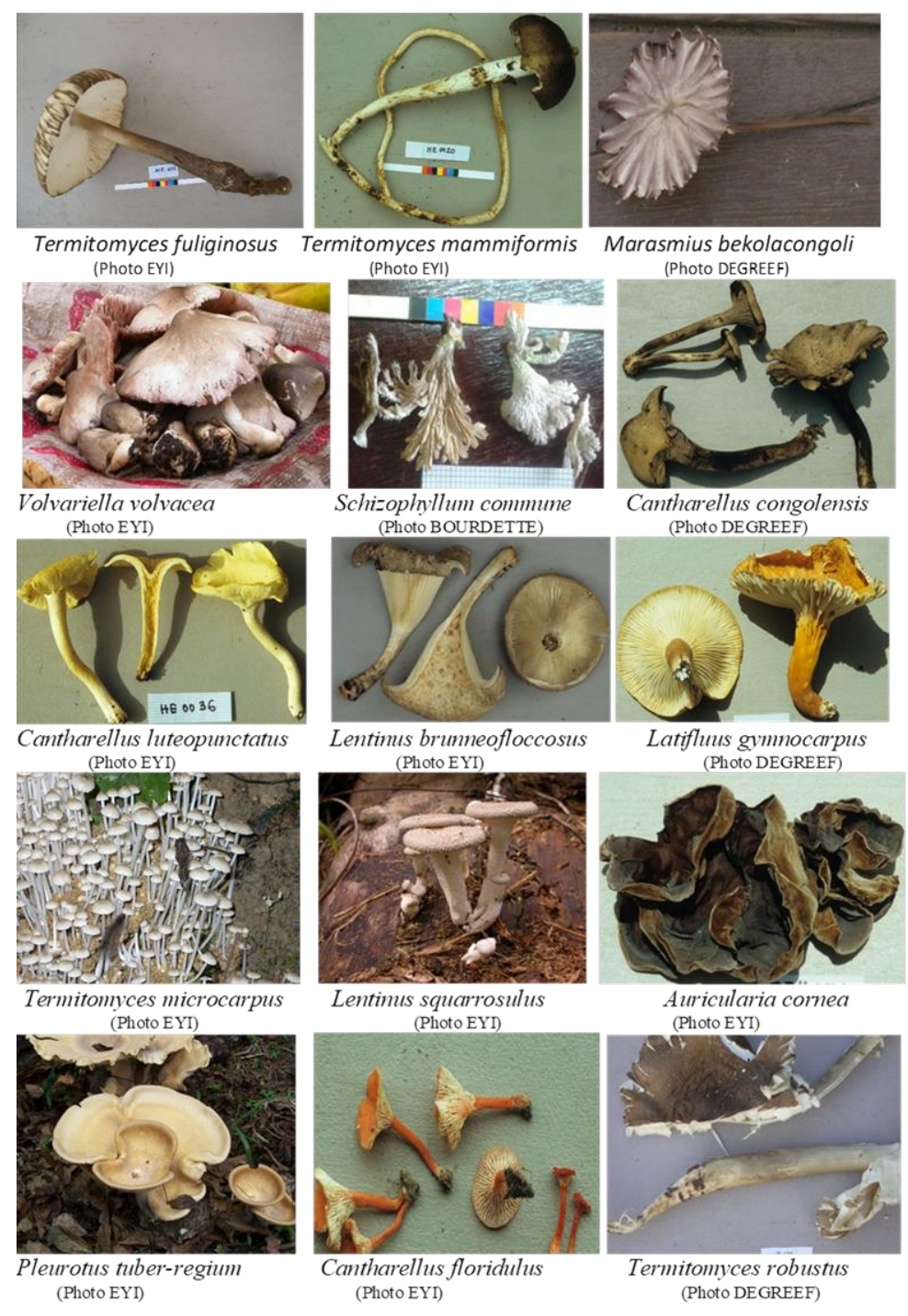

Figure 2 Mushrooms inventoried among the Bakoya, Kota and Kwélé populations. 


\subsection{Number of taxa identified by the respondents according to their ethnolinguistic affiliation}

Table 1 Fungal taxa identified by the ethnic groups studied.

\begin{tabular}{llll}
\hline \multirow{2}{*}{ Taxa } & \multicolumn{3}{l}{ Identified ethnic groups } \\
\cline { 2 - 5 } & Bakoya & Kota & Kwélé \\
\hline Auricularia cornea Ehrenb. & + & + & - \\
Cantharellus congolensis Beeli & - & + & + \\
C. floridulus Heinem. & + & + & - \\
C. luteopunctatus (Beeli) Heinem. & + & - & - \\
Lactifluus gymnocarpus (R. Heim ex Singer) Verbeken & + & - & - \\
Lentinus brunneofloccosus Pegler & + & - & - \\
L. squarrosulus Mont. & + & + & - \\
Pleurotus tuber-regium (Fr.) Singer & + & + & + \\
Marasmius bekolacongoli Beeli & + & - & - \\
Schizophyllum commune Fr. & + & - & - \\
Termitomyces fuliginosus Heim & + & + & + \\
T. mammiformis Heim & + & + & + \\
T. microcarpus (Berk. \& Br.) Heim & + & + & - \\
T. robustus (Beeli) Heim & + & + & + \\
Volvariella volvacea (Bull.) Sing. & + & - & - \\
Number of taxa identified & Key: + = identified species; - = unidentified species & & $\mathbf{5}$ \\
\hline Percentage of taxa & & $\mathbf{9 3 \%}$
\end{tabular}

\subsection{Number of taxa identified by the respondents according to age groups}

Table 2 Fungal taxa identified by respondents by age group.

\begin{tabular}{llll}
\hline Taxa & \multicolumn{3}{c}{ Age groups (years) } \\
& $\mathbf{1 0}$ à 25 & $\mathbf{2 6}$ à $\mathbf{6 0}$ & $>\mathbf{6 0}$ \\
\hline Auricularia cornea Ehrenb. & - & + & - \\
Cantharellus congolensis Beeli & - & + & - \\
C. floridulus Heinem. & + & + & - \\
C. luteopunctatus (Beeli) Heinem. & + & + & + \\
Lactifluus gymnocarpus (R. Heim ex Singer) Verbeken & - & + & - \\
Lentinus brunneofloccosus Pegler & + & + & - \\
L. squarrosulus Mont. & + & + & + \\
Pleurotus tuber-regium (Fr.) Singer & + & + & + \\
Marasmius bekolacongoli Beeli & - & + & - \\
Schizophyllum commune Fr. & - & + & - \\
Termitomyces fuliginosus Heim & + & + & - \\
T. mammiformis Heim & + & + & + \\
T. microcarpus (Berk. \& Br.) Heim & + & + & + \\
T. robustus (Beeli) Heim & + & + & + \\
Volvariella volvacea (Bull.) Sing. & + & + & - \\
Number of taxa identified & $\mathbf{1 0}$ & $\mathbf{1 5}$ & $\mathbf{6}$ \\
\hline Percentage of taxa & Key: + identified species; - = unidentified species & $\mathbf{1 0 0 \%}$ & $\mathbf{4 0 \%}$ \\
\hline
\end{tabular}




\subsection{Number of taxa identified by the respondents according to practiced activities}

Table 3 Fungal taxa identified by respondents according to practiced activities.

\begin{tabular}{|c|c|c|c|c|c|}
\hline \multirow[t]{2}{*}{ Taxa } & \multicolumn{4}{|c|}{ activities practiced } & \multirow[b]{2}{*}{ unemployec } \\
\hline & Agriculture & Hunt & school & peach & \\
\hline Auricularia cornea Ehrenb. & - & + & - & - & - \\
\hline Cantharellus congolensis Beeli & - & + & - & + & - \\
\hline C. floridulus Heinem. & + & + & + & + & - \\
\hline C. luteopunctatus (Beeli) Heinem. & + & + & + & + & - \\
\hline $\begin{array}{l}\text { Lactifluus gymnocarpus (R. Heim ex } \\
\text { Singer) Verbeken }\end{array}$ & - & - & - & - & - \\
\hline Lentinus brunneofloccosus Pegler & - & + & - & + & - \\
\hline L. squarrosulus Mont. & - & + & + & + & + \\
\hline Pleurotus tuber-regium (Fr.) Singer & + & + & + & + & + \\
\hline Marasmius bekolacongoli Beeli & - & + & - & - & - \\
\hline Schizophyllum commune Fr. & + & + & - & - & - \\
\hline Termitomyces fuliginosus Heim & + & + & + & + & - \\
\hline T. mammiformis Heim & + & + & + & + & + \\
\hline T. microcarpus (Berk. \& Br.) Heim & + & + & - & + & + \\
\hline T. robustus (Beeli) Heim & + & + & + & + & - \\
\hline Volvariella volvacea (Bull.) Sing. & + & + & - & + & + \\
\hline Number of taxa identified & 10 & 14 & 7 & 11 & 5 \\
\hline Percentage of taxa & $67 \%$ & $93 \%$ & $47 \%$ & $73 \%$ & $33 \%$ \\
\hline
\end{tabular}

\section{Discussion}

Tables 1, 2 and 3 show that traditional mycological knowledge of these populations varies according to their ethnolinguistic affiliation, their ages and their activities.

\subsection{According to ethnolinguistic affiliation}

Ninety-five out of a hundred and fifty people get good traditional mycological knowledge (Figure 3). These mycological knowledges vary from one ethnic group to another. The results in Table 1 show that Bakoya Pygmies (93\% of the identified species) have a better knowledge about mushrooms than Kota (60\% of the identified species) and Kwele (30\% of the identified species). These data reveal also that almost all the Bakoya (both sexes combined) interviewed have good traditional mycological knowledge, which does not seem to be the case among the Kota and the Kwele. These results are opposite to the results of previous studies in Burundi [2, 3]; in Zimbabwe [10] and Tanzania [7], which indicated that women, traditional mushroom harvesters, knew better the fungi than men, occasional harvesters. This study shows that men of the Kota ethnic group know mushrooms better than women (Figures 3 and 4). 


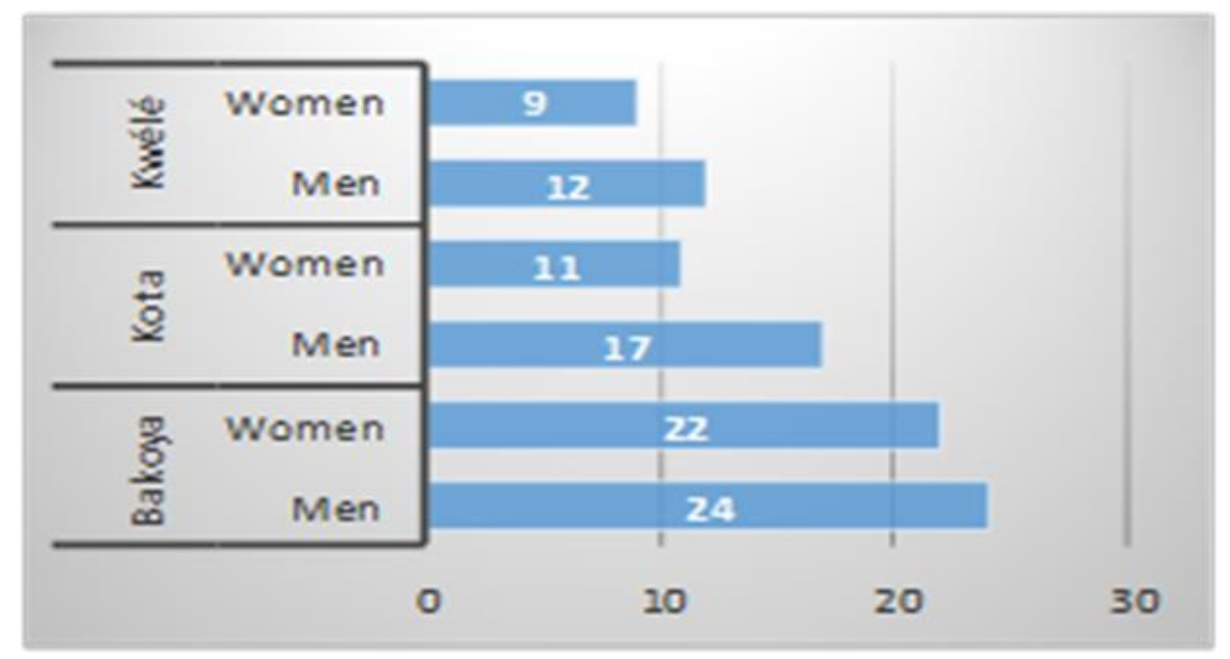

Figure 3 Traditional mycological knowledge distribution according to ethnicity and gender.

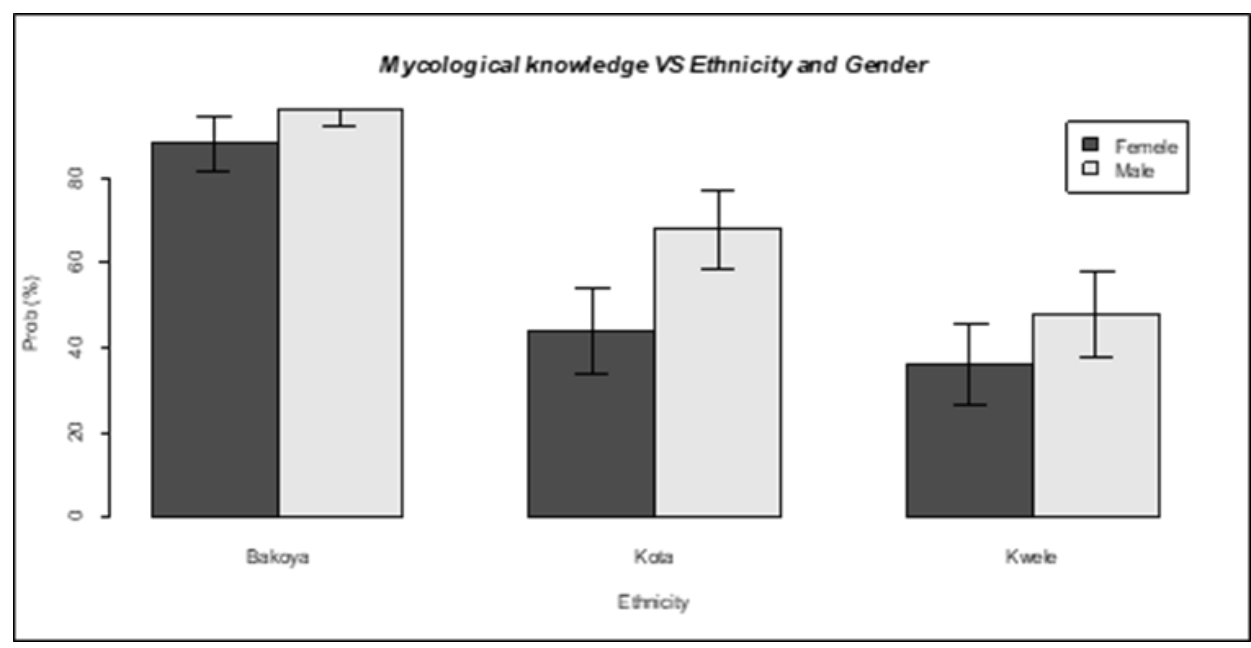

Figure 4 Average response probabilities by modality of the "ethnicity and sex" factor.

Deviance analysis, made possible through the likelihood ratio test, reveals that sex and ethnicity factors have significant effects taken separately; sex (p-value) $=0.03743$; ethnicity $(\mathrm{p}$-value $)=5.349 \mathrm{e}-08$. There is no significant effect of the gender-ethnicity interaction ( $\mathrm{p}$-value) $=0.78008$, however. This confirms the results in Table 1 which shows that the best traditional mycological knowledge is held by pygmies, followed by kota. Figure 4 shows that within ethnic groups, there is no significant difference between the sexes, with the exception of the Kota group within which we notice that men have better mycological knowledge. However, this apparent finding is not statistically significant.

Indeed, Pygmies who for the most part live only on hunting and gathering test the taste and regularly adopt new edible species in times of scarcity; therefore, they know many more species of fungi than Bantus. On the other hand, the mistrust towards mushrooms pushes Bantus to consume only the taxa the more common, generally belonging to Cantharellus, Termitomyces, Lentinus and Pleurotus genus, as well as the few rare taxa sold on local markets.

\subsection{According to age groups}

Eighty-seven of one hundred and fifty respondents had good traditional mycological knowledge (Figure 5). Table 2 shows that the best knowledge was held by the representatives of active population (26-60 years old) who identified all of inventoried species in their region compared to young people who identified only $67 \%$ and people from the third age which recognize $40 \%$ of inventoried species. Furthermore, according to these data, almost all people aged 26 to 60 have good traditional mycological knowledge. 


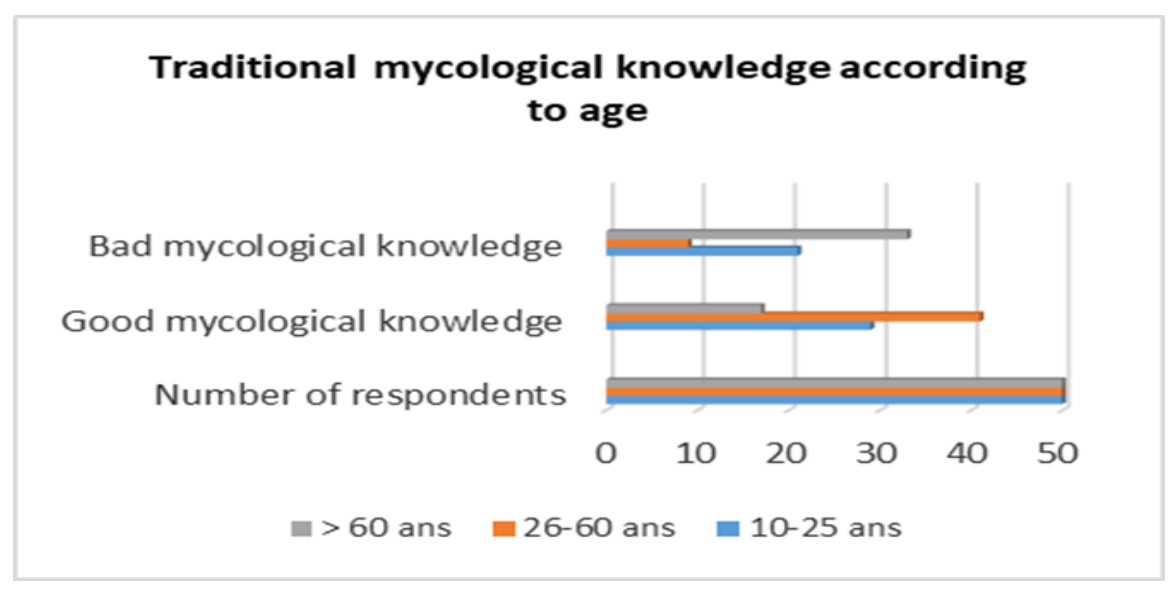

Figure 5 traditional mycological knowledge distributions according to age.

The likelihood ratio test revealed a highly significant effect of age factor on traditional mycological knowledge, at the threshold of 0.01 ( $\mathrm{p}$-value) $=4.087 \mathrm{e}-06$. All the average response probabilities corresponding to the different modalities of age factor are statistically different (Figure 6). The age group "26-60 years" has the best probability $=0.87$ (p-value $=0.0001)$, it corresponds to individuals proportion which have the best traditional mycological knowledge. On the other hand, the age group of 61 years and over has a very poor traditional mycological knowledge ( $p$-value $=0.0263$ and probability $<0.5$ ). The significance test of the means showed that for people aged 10 to 25 years, there is statistically an equiprobability between good and bad answers ( $\mathrm{p}$-value $=0.2600$ and probability $\approx 0.5$ ).

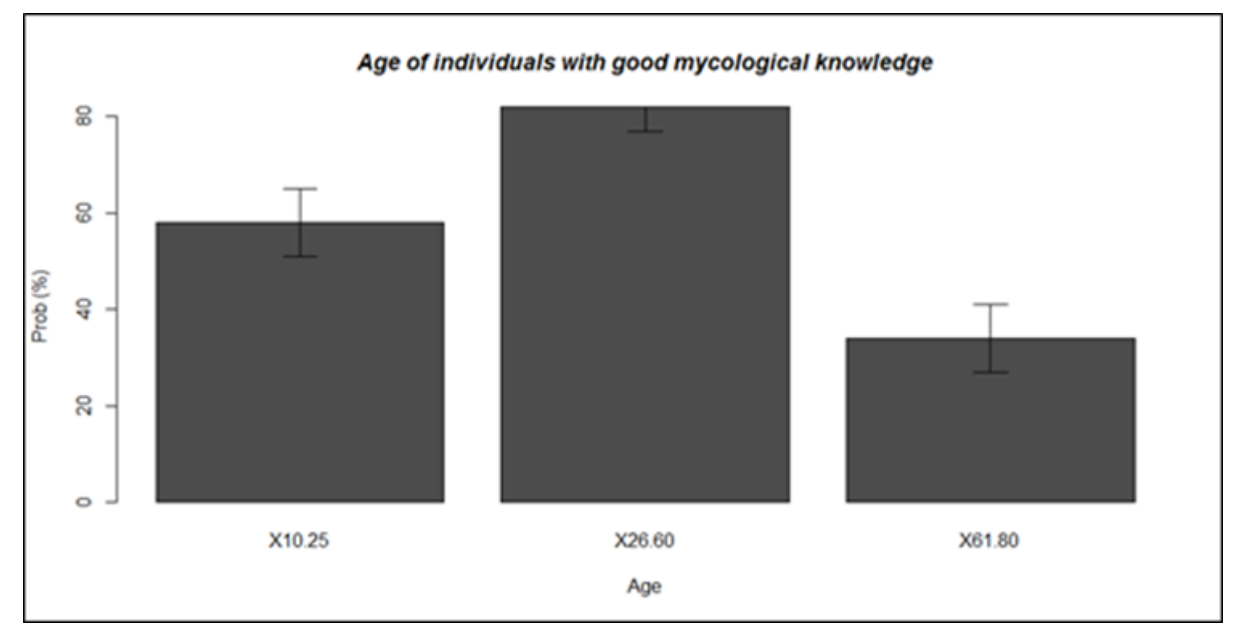

Figure 6 Average response probabilities by age factor modality.

According to [5], the elderly would generally know more species of wild edible mushrooms than the young in Benin. However, our study, reinforced by statistical analysis of data, shows that people between the ages of 26 and 60 and young people have better traditional mycological knowledge than old people. Indeed, people aged 26 to 60 years are mainly hunters, fishermen, and farmers whose forest exploitation is a main activity; as a result, they are very familiar with the forest products exploited by their ethnic groups, including mushrooms. Young people with good traditional mycological knowledge are mainly Bakoya (Pygmies) whose mushrooms knowledge is cultural. In contrast, the elderly harvest mushrooms only occasionally, so they only know the mushrooms frequently harvested by the usual collectors and which are generally sold in the village. In our study area, mycological knowledge of the elderly is likely to be lost due to inactivity or loss of vision. The same observation was reported in Tanzania [7].

\subsection{According to the activity practiced}

Table 3 shows that hunters identified almost all of the inventoried species (93\%) followed by fishermen (73\%) and farmers (67\%), while schoolchildren and invalids barely managed to identify half of inventoried species. Furthermore, Figure 7 indicates that almost all of the hunters interviewed have good traditional mycological knowledge, while only 
half of the fishermen and farmers have good mycological knowledge, but very few students and disabled people manage to identify the mushrooms inventoried in their locality.

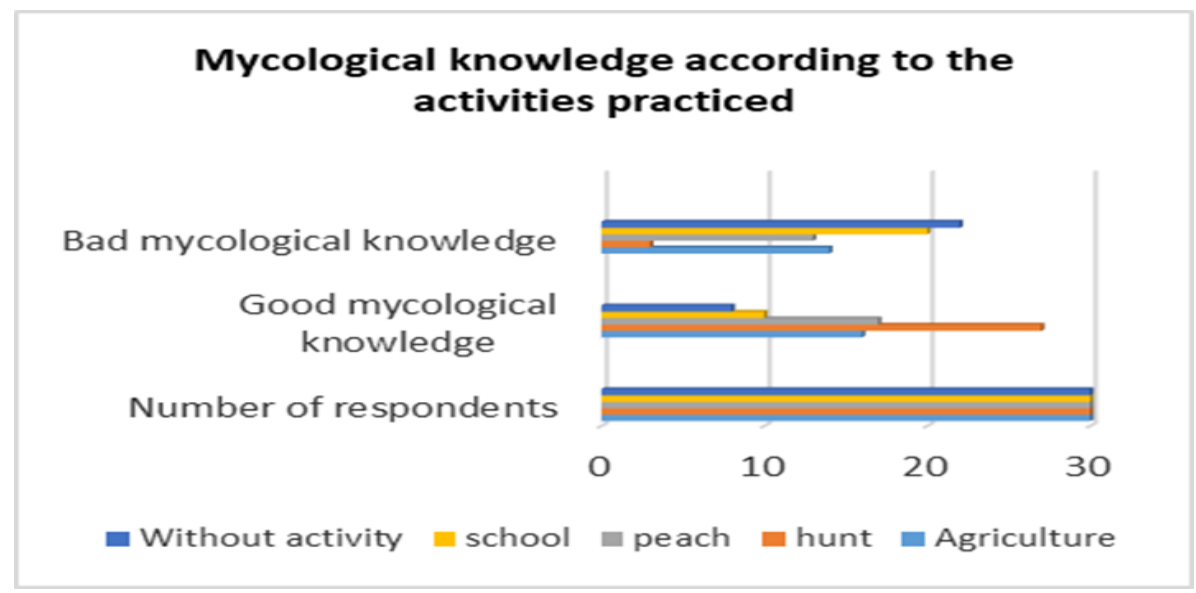

Figure 7 Traditional mycological knowledge distribution according to the activity practiced.

Statistical analysis of data shows that the activity practiced by populations also has a highly significant effect on traditional mycological knowledge $(p$-value $)=1.373 \mathrm{e}-06$. The two-by-two comparison of different methods means makes it possible to identify three distinct homogeneous groups. The first made up of hunters. The second, is made up of farmers and fishermen and the third is made up of invalids (or without activity) and schoolchildren. People who hunt have the best traditional mycological knowledge ( $p$-value $=0.00366$, probability $=0.90$ ), followed by fishermen and farmers ( $\mathrm{p}$-value $\approx 0.7$ and probability $\approx 0.6$ ). Finally, the inactive and the schoolchildren ( $\mathrm{p}$-value $\approx 0.5$ and probability $\leq 0.12$ ) (Figure 8).

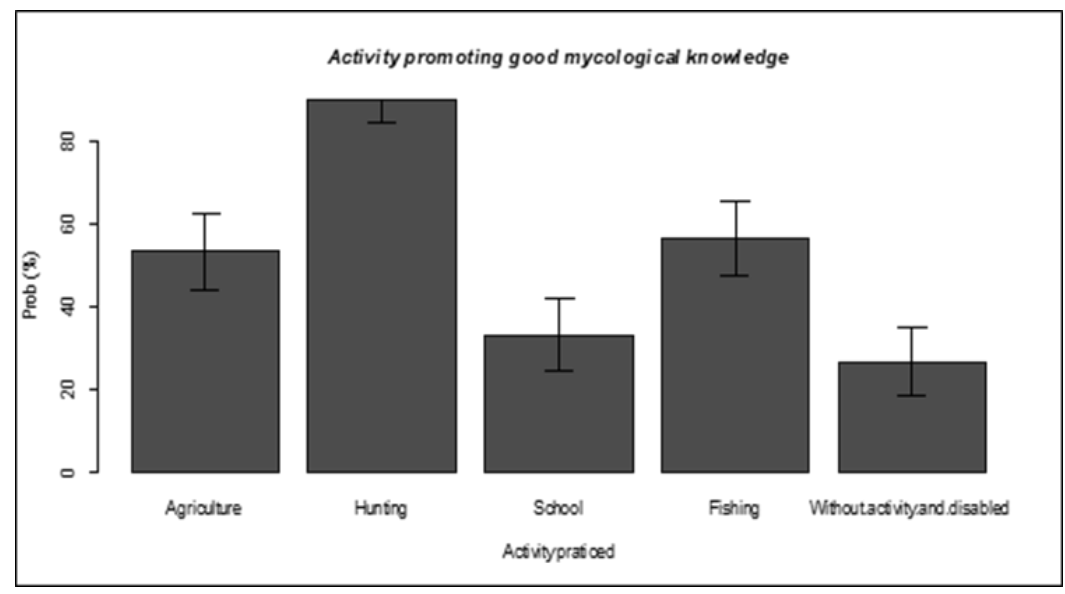

Figure 8 Average response probabilities by modality of "Activity practiced" factor.

Indeed, in the studied area, Pygmies and Bantus practice the selected activities differently; hunting, fishing and gathering are the main Pygmies activities while farming, hunting and fishing are the main Bantus activities. Hunters, who are in constant contact with the forest have a perfect knowledge of edible mushrooms they pick for their own consumption or for sale along the roads. They are essentially pygmies. Their mushrooms knowledge is cultural and each individual is a traditional mushroom harvester. Fishing and hunting being seasonal, fishermen and farmers mainly made up of Bantus knowing fewer mushrooms than hunters.

With the exception of a few girls who learn to recognize mushrooms from their mothers during weekends and public holidays, pupils who, for the most part study in the city, have very little traditional mycological knowledge $(47 \%$ of identified taxa). The more you go to school, the less you know about mushrooms; as a result, very few young people manage to recognize mushrooms which they consume regularly, but which are harvested by their parents in the majority of cases. The same observation was reported in Tanzania [7] and in Benin [5]. Most of the disabled people interviewed were bedridden, who could no longer recognize the fungi, presumably due to loss of sight. 


\section{Conclusion}

The results of our study show that the traditional mycological knowledge of studied populations varies according to ethnolinguistic membership, age and practiced activities. Pygmies traditional mycological knowledge is more developed than Bantus's. However, statistical analysis of data shows that mycological knowledge of men and women are similar within different ethnic groups. In terms of age groups, representatives of the working population and young people know more species than older people. Depending on the activity, hunters know the mushrooms better than fishermen and farmers; and the latter know better than pupils and invalids. Almost all of hunters interviewed have good traditional mycological knowledge, while schoolchildren and invalids barely manage to identify half of the inventoried species.

Apart from the Pygmies who organize themselves to go in search of mushrooms for their own consumption, Bantus never go out into the forest solely to harvest the mushrooms since the mushroom harvest period generally coincides with the work in the fields. Picking mushrooms is therefore not a commercial activity in our study area despite the abundance of wild edible mushrooms in the rainy season. The sale of mushrooms along the roads is done occasionally during periods of abundant fruiting.

\section{Compliance with ethical standards}

\section{Acknowledgments}

The authors thank the Gabonese Government, the Meise Botanical Garden of Belgium, and the European Union for their material and financial support.

\section{Disclosure of conflict of interest}

The authors declare that they have no conflict of interest.

\section{Statement of ethical approval}

This study has been approved and supported by the National Center for Scientific and Technological Research. Field activities were conducted in accordance with guidelines from local authorities.

\section{References}

[1] Boa ER, Ngulube M, Meke G, Munthali C. First Regional Workshop on Sustainable Use of Forest Products: Miombo Wild Edible Fungi. Zomba, Malawi, Forest Research Institute of Malawi and CABI Bioscience. 2000.

[2] Buyck B. Ubwoba: Les champignons comestibles de l'ouest du Burundi. Brussels. Administration Générale de la Cooperation au Développement. 1994.

[3] Buyck B, Nzigidahera B. Ethnomycological notes from Western Burundi. Belg. Journ. Bot. 1995; 128(2): $131-138$.

[4] Degreef J, Malaisse F, Rammeloo J, Baudart E. Edible mushrooms of the Zambezian woodland area: a nutritional and ecological approach. BASE. 1997; 1: 221-231.

[5] De Kesel A, Codjia JTC, Yorou SN. Guide des champignons comestibles du Bénin. Cotonou, République du Bénin: Jardin Botanique National de Belgique et Centre International Eco développement Intégré (CECODI). 2002.

[6] Eyi Ndong HC, Degreef J, De Kessel A. Champignons comestibles des forêts denses d'Afrique centrale Taxonomie et Identification. Jardin Botanique Meise, Belgique: Abc Taxa 10e éd. 2011.

[7] Härkönen M, Saarimäki T, Mwasumbi L. Edible mushrooms of Tanzania. Karstenia. 1995; 35: 1-92.

[8] Morris B. Bowa: Ethnomycological notes on the macrofungi of Malawi. In Seyani JH \& Chikuni AC (eds). Proceedings of the XIIIth Plenary meeting of AETFAT. 1 éd. National Herbarium and Botanic Gardens, Zomba, Malawi. 1994; 635-647.

[9] Oso BA. Mushrooms and the Yoruba people of Nigeria. Mycologia. 1975; 67(2): 311-319.

[10] Piearce GD, Sharp C. Vernaculaire names of Zimbabwean fungi: a preliminary checklist. Kirkia. 2000; 17(2): 219228.

[11] Richards A. Land, Labour and Diet in Northern Rhodesia. An economic study of the Bemba tribe. Oxford University Press, London. 1939. 
[12] Sayer JA, Harcourt CS, Collins NM. The conservation atlas of Tropical Forests: Africa. Gland: IUCN. 1992.

[13] Thoen D, Parent, Lukungu T. L'usage des champignons dans le Haut-Shaba (République du Zaïre). Bull. Trim. Centr. Etudes Probl. Soc. Econ. (CEPSE) «Problèmes sociaux zaïrois». 1973; 100-101: 69-85.

[14] R Core Team. Un langage et un environnement pour le calcul statistique. Vienne: Fondation R pour le calcul statistique. 2018.

[15] Hervé M. Aide-mémoire de statistique appliquée à la biologie: Construire son étude et analyser les résultats à l'aide du logiciel R. 2016.

[16] Wassermann L. All of Statistics: A Concise Course in Statistical Inference, New York, Springer-Verlag. 2004. 